\title{
A INFLUÊNCIA DO TUPI NA LINGUAGEM POPULAR REFERENTE AO MEIO AMBIENTE DO LITORAL SUL DE PERNAMBUCO, BRASIL
}

\author{
Maria do Carmo Ferrão SANTOS \\ Bióloga do IBAMA/CEPENE \\ Beatrice Padovani FERREIRA \\ Departamento de Oceanografia da UFPE
}

\begin{abstract}
RESUMO
Este trabalho foi elaborado para fornecer de informações sobre a origem de 94 palavras provenientes da língua tupi, cujo uso é bastante comum quando trata-se de meio ambiente do litoral sul de Pernambuco. Assim, além de conhecer a influência tupi na linguagem popular pernambucana, podemos melhor compreender a grandeza que representava a natureza para os primeiros habitantes desse litoral, que ainda hoje, são para as modernas gerações, verdadeiros exemplos de ambientalistas.

Palavras chaves: Tupi, linguagem popular, meio ambiente.
\end{abstract}

\section{ABSTRACT \\ The Influence of the Tupi in the popular Language Related to the Environment and South Littoral of Pernambuco, Brazil}

The present paper is a contribution to the knowledge of the origin of 94 words related to the environment in South Pernambuco. The meaning in Tupi, language of the native inhabitants of Brazil, was investigated. In addition to understanding the original signification of the noums, this is a testimony to the relationship between the native brazilions and their envronment, and the legacy lefe to the future generations.

Key words: Tupi, language, popular, environment

\section{INTRODUÇÃO}

O termo "descobrimento" para se referir à chegada dos portugueses no Brasil em 1500 é impróprio, se considerarmos que os portugueses não encontraram aqui uma terra desabitada, mas povoada há séculos, por pessoas que aqui moravam, tinham uma cultura própria e desenvolviam uma civilização. Em 1549, quando o primeiro governador-geral, Tomé de Sousa, chegou ao Brasil, veio acompanhado por diversos jesuítas, os quais estavam sob o comando do padre Manuel da Nóbrega. Esses religiosos atuaram diretamente na "nação indígena" até 1759, quando foram expulsos do Brasil, pelo marquês de Pombal.

Nesse período de 210 anos, os jesuítas promoveram uma ação maciça na catequese dos índios, porém, foi difícil o trabalho de instalar um sistema de educação em terra estranha e de povo tribal. Assim, o primeiro jesuita a aprender o tupi foi Aspilcueta Navarro. O referido religioso divulgou rapidamente o conhecimento adquirido para outros jesuítas. Em 1553, quando o noviço José de Anchieta chegou ao Brasil, ficou encarregado de organizar a primeira gramática no idioma dos nativos, como forma de divulgar a língua dos primeiros habitantes e, desta forma, facilitar a aprendizagem entre os padres (ARANHA, 1996).

Trab. Oceanog. Univ. Fed. PE, Recife, 28(1): 87- 96, 2000. 
Na visão de BUENO (1983), o tupi foi a língua mais usada pelos jesuítas em suas catequeses. Não foi língua própria de uma tribo, mas uma uniformização léxica racional de vários dialetos, fixada pela Gramática do padre José de Anchieta e pelo vocabulário jesuítico. Foi o tupi o resultado desse esforço normativo para servir a todos os missionários em seus trabalhos e por toda a costa atlântica, entre o Maranhão e São Paulo. Assim, o tupi foi a língua legítima dos índios e não se confudia com os colonos que aqui vieram habitar. O Guarani foi um dos dialetos do tupi, o qual foi falado desde São Paulo até o Paraguai.

TIBIRIÇÁ (1984), menciona que, ao contrário do que geralmente se pensa, não existe um idioma tupi, mas vários dialetos que trazem este nome. Sobre o tupiguarani, o autor afirma que não existe esta língua, pois, o tupi-guarani diz respeito ao tronco étnico, do mesmo modo como nos referimos ao indo-europeu, portanto, o tupiguarani é um conjunto de dialetos falados em quase todos os países da América do Sul. E que, na região norte do país, ainda hoje, existe o uso de um tupi moderno (neo-tupi).

De acordo com a autora, tornou-se tão comum falar em tupi, que ficou conhecida como "língua geral", nhenheugatu. O idioma tupi foi a língua materna de uso corrente até meados do século 18 , primeiro como língua de comunicação dos europeus com os Tupinambás de toda a costa brasileira depois como,língua materna dos mamelucos da Bahia, Pernambuco, Maranhão e São Paulo (RIBEIRO, 1995). Este procedimento perdurou por algum tempo, até que as autoridades portuguesas, temerosas de que a língua nativa predominasse no país, passaram a exigir o uso exclusivo do português.

Verifica-se, contudo, que mesmo com esse impedimento de se falar em tupi, as nominações dadas pelos indígenas com relação aos rios, localidades, utensílios, aos seres vivos, etc., são utilizadas até hoje, embora muitas vezes, de forma aportuguesada. Observa-se assim, que o conhecimento lingüístico ficou no passado, pois desse idioma pouco se sabe ou é divulgado, porém, as nominações utilizadas pelos nativos foram relativamente preservadas.

Os grupos indígenas encontrados no litoral brasileiro eram principalmente tribos do tronco Tupi, e somavam talvez 1 milhão de índios (RIBEIRO, 1995). De acordo com CARVALHO (1907), quando no Brasil desembarcaram os portugueses, habitavam Pernambuco, duas ou mais raças distintas. No litoral e na zona vizinha, residiam, em agrupamentos relativamente estáveis, os tupis das tribos Caetés e Tabajaras, que já tinham expulsado para o interior do continente, os Tapuias ou Gê e Cariris, que aqui viviam anteriormente. Os índios dependiam da caça e pesca para obter alimentos, daí a importância de sítios privilegiados, onde os recursos abundantes garantiam a sobrevivência do grupo e permitiam manter aldeamentos maiores. Em certos locais, especialmente ricos da costa, excepcionalmente, os aldeamentos chegavam a alcançar 3 mil pessoas (RIBEIRO, 1995)

O litoral sul de Pernambuco, com a presença de vários ecossistemas de alta produtividade como a mata Atlântica, manguezais, estuários e recifes de corais provavelmente era um destes sítios. Esta interação se reflete na grande variedade de denominações de origem tupi que ainda hoje perduram ao estudarmos o Meio Ambiente do litoral sul de Pernambuco. Este vocabulário é muito rico em palavras, porém, com escasso material bibliográfico que forneça informações quanto à interpretação do 
idioma. Desta forma, o presente trabalho é uma contribuição para a influência do tupi no litoral sul de Pernambuco.

Com o prosseguimento dessa linha de trabalho, poderemos recuperar o nível de conhecimentos e crenças que os nativos pernambucanos tinham em relação ao meio ambiente, além, de contribuir com a ampliação cultural dos atuais ecologistas.

Este trabalho torna-se urgente, tendo em vista que, as alterações cotidianas vão tornando cada vez mais indecifráveis o idioma tupi para as modernas gerações. Além disso, diversas línguas faladas no país, no período da chegada dos portugueses, com o passar do tempo desapareceram sem serem documentadas, representando um prejuízo irreparável para a linguística e várias ciências que se dedicam ao estudo do homem.

\section{MATERIAL E MÉTODOS}

A referida pesquisa consiste em um levantamento bibliográfico, realizado no período de março a novembro de 1999, sobre a origem dos nomes utilizados pelos índios que povoavam esse litoral, antes do seu "descobrimento".

Os 94 topônimos tupis aqui apresentados foram baseados nos trabalhos de CARVALHO (1907), MELO (1971), BUENO (1983), COSTA (1983), TIBIRIÇÁ (1984), RIBEIRO, B. G. (1988), CUNHA (1998), do Núcleo de Estudos Indigenistas (NEI) da Universidade Federal de Pernambuco e através de consultas ao Dr. Joubert Di Mauro, estudioso do idioma tupi - USP.

No presente trabalho não houve um aprofundamento sobre as raízes que originaram o idioma aqui estudado, apenas como forma de melhor entendimento sobre o tupi, foram registrados os comentários supracitados, oriundos de diferentes autores. Entretanto, levou-se em consideração a sua forma original, ou seja, como a palavra era interpretada e redigida e o seu significado para a nação indígena, pois dessa forma podemos entender a força da natureza sobre os índios e a riqueza natural que cercava aquele ecossistema, já que algumas nominações foram dadas em função da biodiversidade que existia naquela ocasião, no entorno do ambiente nominado.

\section{RESULTADOS E DISCUSSÃO}

O tupi para CARVALHO (1907) foi uma língua aglutinante, com os elementos componentes quase integrais. Assim, a palavra nesse idioma com facilidade se analisa.

O resultado dessa pesquisa encontra-se em ordem alfabética, como forma de facilitar as consultas.

Encontram-se abaixo relacionados em ordem alfabética, os nomes de origem indígena, bastante utilizados ao sul do litoral pernambucano. Cada palavra vem seguida da nomenclatura em tupi e o significado para o povo indígena.

ABACAXI (fruta da planta de família das bromeliáceas) - iuaka-ti = fruta recendente, a que emite cheiro agradável e penetrante.

AÇU (nome vulgar dado a uma espécie de sirí) - uasú = grande ou volumoso. 
AMARAGI (rio existente no munícípio de Sirinhaém e uma propriedade rural do município do Rio Formoso) - amã-rá-gy = rio procedente de chuva, água temporária.

ARABAIANA (peixe da família Carangidae) - iu-rumbaia-nã = contém espinhos trançados e misturados, o que brilha.

ARAÇÁ (fruto do vegetal da família das mirtáceas) - ya-reçá = o fruto que tem olho.

ARAGUÁRA (riacho existente no município de Sirinhaém) - ará-quára = viveiro ou refúgio dos papagaios.

ARATU (crustáceo da família Grapsidae) - ára-tu = o tombo de cima, que ao menor ruído se joga do alto.

ARIOCÓ (peixe da família Lutjanidae) - ari-acó = aquele que é pequeno.

ARIPIBÚ (rio existente no município de Barreiros) - ára-ypibú = fonte que resiste a seca.

ARIQUINDÁ (rio que situa-se na margem esquerda do rio Formoso) seu primeiro nome foi Aracondá -ara-cundá $=0$ pássaro enroscado, emaranhado, atado ou embaraçado.

BAIACU (peixe da família Tetraodontidae e Diodontidae) - mbaé-açú = aquele que é quente.

BIJUPIRÁ (peixe da família dos Rachicentridae) - miiuipi-ra = certo peixe voador.

BIQUARA (peixe da família Haemulidae - yby-guará = o que come terra.

BOACICA (propriedade rural do município de Ipojuca) - mboi-acig = cobra de duas cabeças.

BOISSÓ (riacho do município de Sirinhaém) - mboy-yçog = piolho de cobra.

BURARAMA (propriedade rural do município de Sirinhaém e de Rio formoso) ybyrá-rama $=$ terra das árvores ou região de mata

CABUÇU (riacho do município do Rio Formoso) - caba-uçú = vespa grande.

CAIÇARA (local onde se recolhem as jangadas e os aparelhos de pesca e também uma arte de pesca onde varas são enterradas formando um cerco para captura de peixes) cayssára $=$ cerca de ramos, fortificação.

CAJÁ (fruto do vegetal da família das anacardiáceas) - acã-yá = fruto de caroço cheio. 
CAJU (fruto do vegetal da família das anacardiáceas ) - acâ-yú = o pomo (fruto carnudo) amarelo.

CAMURIN (peixe da família Centropomidae.) - kamu-ri = o cabeça pequena.

CAMURIGIMIRIN (riacho do município de Sirinhaém) - camuri-g-y-mirim = pequeno rio dos camorins.

CAPIM (plantas gramíneas e ciperáceas) - cáa-piyn = mato fino.

CAPIVARA (mamífero da família dos hidroquerídeos) - kapii'üara = comedor de capim.

CAPOEIRA ( terreno onde já houve roça e que foi invadido pelo mato) - ko'puera = roça velha, abandonada.

CARAPEBA (peixe da família dos Encinostomida.) - acará-peba = cabeça áspera e chata.

CARAPICU (peixe da família Gerreidae) - akaràpu-hu = peixe cascudo e longo.

CARAUNA (peixe da família Acanthuridae) - cara-una = peixe rugoso e preto.

CARIMAN (afluente do rio Una, passa pelo município de Barreiros) - quirin-mã = punhado brando, macio.

CHANGUÁ (propriedade rural do município do Rio Formoso) - cang-guá = vale dilatado ou estendido.

CIPÓ (plantas sarmentosas ou trepadeiras) - içá-po = a fibra que se agarra.

COCAU (usina do município do Rio Formoso e riacho do município de Sirinhaém) coca-u $=$ rio dos viveiros .

COITÉ (fruto da árvore da família das bignoniáceas, também chamada cabaceira) cui-eté $=$ a cuia exelente.

CUIA (metade da casca do fruto da árvore da família das bignoniáceas) - kui-aua = casca cortada ao meio.

CUPIM (designação geral das térmitas) - cô-pii = corta a roça.

CURIÓ (ave da família dos gruigílidas) - curí-ú = o come ligeiro. 
CUTIA (roedor da família dos cávidas) - a-coti = o que se senta.

EMBIRA (corda de cipó ou de casca de árvore) - ymbyra = casca fina.

GAMBÁ (nome comum a vários marsupiais) - ygué-ambá = barriga oca.

GAMBOA (pequeno trecho de rio, igarapé) - caá-mbó = o feixe de mato ou cinta de ramagem.

GINDAÍ (rio do município do Rio Formoso) - nhendai-hy = rio das jandaias.

GUAIAMUM (crustáceo da família Gercacinidae) - guayá-m-u = caranguejo azulado.

GORANA (peixe da família Sphyraenidae) - go-rana = o que é falso.

GRAUÇÁ (também conhecido por maria-farinha, da família Ocypodidae) - coará-uça $=\mathrm{o}$ caranguejo do buraco.

GUAJA (crustáceo Brachyura) - goá-i-á = o que é redondo.

IGARAPÉ (estreito canal natural no leito do rio) - igara-ape = o caminho das canoas.

ILHETAS (rio que passa pela propriedade rural com o mesmo nome, no município de Tamandaré) - Antes de Ilhetas, seu antigo nome era Itaguassutiba - itaguaçú-tyba $=0$ penhasco.

IPOJUCA (rio e município do litoral sul de Pernambuco) - yapó-yuc = estagnado, podre.

JABUTICABA (fruto da árvore da família das mirtáceas) - iapoticaba = frutas em botão.

JACARÉ (réptil da família dos crocodílideos) - yaka-ré = lagarto d'água.

JARARACA (cobra da família dos crotalídeos) - yará-r-ag = tem bote venenoso.

JENIPAPO (fruto do jenipapeiro) - nhandipab = fruta de esfregar ou que serve para pintar.

JERERÉ (aparelho de pesca de camarão e peixe miúdo) - yerê-rê = propenso a girar.

LOCA (buraco onde peixes e outros animais se refugiam) - roca $=$ a casa dele.

MANGABA (fruto da mangabeira) - mong-aba = o visgo, o grude. 
MAMUCABA (propriedade rural do município de Tamandaré) - mamõ-cai = a cerca queimada, o fecho que se queimou.

MANJUBA (peixe da família Atherinidae) - man-yúba = o envolto amarelo.

MARIMBONDO (nominação dada a diversas espécies de vespas) - mberú-ybõ = mosca que flecha.

MUÇUM (designação de várias espécies de enguias) - m-cym = o que desliza, viscoso, escorregadio.

MARUIM (mosquito da família dos quironomídeos) - mari-üi = o que morde.

MATURI (o cajú em formação) - ibá-tiriri = fruto minguado, pequeno.

PARU (peixe da família Pomacanthidae) - pir-ú = o pele negra.

PERERECA (espécie de batráquio) - pere-reka = ir aos saltos.

PERNAMBUCO (Estado nordestino) - paranã-buc $=$ o mar quebra, o mar arrebenta, isto é, o quebra mar em alusão aos recifes.

PERSINUNGA (rio utilizado como limite entre os estados de Pernambuco e Alagoas, entre os municípios de São José da Coroa Grande e Maragogi) - piraçununga = onde o peixe rumoreja, produz ruído surdo, sussurra macio.

PIABA (designação dada a peixes bastante pequenos) - pi-ab = o que corta ou belisca a pele.

PIRAÚNA (peixe da família Serranidae) - pirá-una = o peixe preto.

PITANGA (fruto da planta da família das mirtáceas) - pitang = vermelho

PITOMBA (fruto da planta da família das sapindáceas) - pitã-yba = o fruto da casca encorpada.

PITU (camarão de água doce da família Palemonidae) - pi-t-u = o casca escura.

PREÁ (roedor de pequeno tamanho) - apérea = o que mora no caminho.

PUÇÁ (pequeno apetrecho de pesca artesanal, utilizado na captura de pitu, camarão, siri, etc) - pyça $=$ introduzido, atolado, metido.

RIO FORMOSO ( rio que passa pelo município do mesmo nome) seu primeiro nome foi Iobuguassu - y-obi-guassú $=0$ grande rio verde. 
SABIÁ (ave da família dos turdídeos) - soó-biá = o animal agradável.

SAGÜIM (pequeno macaco de cauda felpuda e comprida ou família?) - ça-soi = os olhos inquietos ou vivos.

SAMAMBAIA (planta da família dos polipodiáceas) - çama-mbai = o trançado de cordas.

SANHAÇU (ave da família dos traupídeos) - saia-su = ave grande.

SAUÉ (distrito de Tamandaré) - içaú-é = a formiga mestra.

SAÚNA (taínha pequena da família Mugilidae) - sá-u-na = os olhos pretos.

SERRAMBI (área costeira do município de Sirinhaém) - ceri-nambi = o marisco.

SIRI (Brachyura: Portunidae, que ocorre nos estuários e ambientes marinhos ao sul de Pernambuco) - ciri = ao que corre, o corredor.

SIRINHAÉM (município do litoral sul de Pernambuco) - ciri-nhaen = a vaso (canal em que circulam nutrientes para animais e vegetais) ou viveiro dos siris.

SURUBIM (peixe da família Siluridae) - ju-rubi = a boca pequena ou fechada.

SURURU (molusco comestível da família dos mitílidas) - çoo-rurú = o bicho úmido.

TACIS (recifes submersos ao largo do litoral sul de Pernambuco) - itá-acir = a pedra pontuda.

TAMANDARÉ (município do litoral sul de Pernambuco) - Os historiadores citam duas traduções quanto a origem dessa palavra:

1- É uma corruptela de tamoindaré. Que significa o repovoador. Na tradição dos índios tupis, existia a crença de que Tamandaré era um pajé (chefe espiritual), a quem Tupã (nome que os índios davam ao trovão, e que passou, mais tarde, a designar Deus) revelara o seu propósito de exterminar os homens. Assim, quando houve o cataclismo que inundou a Terra, Tamoindaré foi o escolhido por Tupã para repovoar toda a área afetada, assim, o abrigou numa arca gigantesca com sua família e diversas espécies.

2- É uma corruptela de tamanduaré. O que se assemelha ao tamanduá, o que sobe às árvores como o tamanduá, o que faz o papel do tamanduá; nome do Noé dos selvagens na sua lenda do dilúvio.

TANAJURA (fêmea alada da formiga saúva) - tã-ayura = a formiga vinda, a que sai do formigueiro. 
TATU (designação comum a várias espécies de mamíferos da família dos dasipodídeos $)$ - ta-tu = o casco duro ou encorpado.

TATUÍ (crustáceo da família dos hipideos) - tatu-í = o tatu pequeno.

TIBIRÍ (rio que corta o município de Barreiros) - É uma corruptela de tyby-r-y = a rio das covas ou das sepulturas.

TINGUÍ (doenças das vias respiratórias provocadas, temporariamente, nos seres humanos, por cianofíceas existentes no mar - principalmente da cidade de Tamandaré) timbó = a planta venenosa que mata peixe. De acordo com HEIZER (1986), quanto às pescarias, os índios tinham um velho hábito cultural, em toda a América do Sul, de usar venenos vegetais, onde de uma forma geral, essas plantas eram nominadas de timbó. No Brasil, o autor mencionou o uso de 66 espécies, seguido da Guiana com 22 espécies.

TRAÍRA (peixe de água doce) - taranira = peixe voraz.

UNA (um dos rio mais importante do litoral sul de Pernambuco. Sua foz encontra-se no município de Barreiros) - $\mathbf{y}$-una $=$ o rio preto.

XARÉU (peixe da família Carangidae) - xarauá = o deixado, o abandonado.

PALÁCIO (1987), menciona que no Nordeste, praticamente já não existe língua indígena ativa além do Yatê, falada pelos índios Fulniô, em àguas Belas, no Estado de Pernambuco. Os demais grupos indígenas nordestinos, aparentemente, perderam esse traço cultural. De acordo com a Fundação Nacional de Saúde (1996), em Pernambuco existem 116 aldeias indígenas, localizadas no agreste ou sertão do estado, totalizando numa população de 19.130 índios, pertencentes a oito diferentes etnias (Atikum, Fulni-ô, Kambiwá, Kapinawá, Pankararú, Truká, Tuxá e Xucuru), destas, apenas a Fulni-ô possui índios que ainda preservam a sua língua nativa, o Yatê. Assim, podemos verificar que praticamente todo o povo indígena que ocupa a região Nordeste, já perdeu suas raízes lingüísticas, tornando desta forma, ainda mais importante a concretização desse trabalho de investigação histórica como testemunho para as modernas gerações.

\section{AGRADECIMENTOS}

À Antônio Fernandes Dias (do IBAMA/CEPENE) pela busca de informações via INTERNET e à amiga Clara (funcionária do Núcleo de Estudos Indigenistas (NEI) da Universidade Federal de Pernambuco) pelas orientações oferecidas.

\section{BIBLIOGRAFIA CONSULTADA}

ARANHA, M. L. A. História da educação. Ed. Moderna. São Paulo, 1996. 255p. BUENO, F. S. Vocabulário tupi, guarani, portugues. ed. Gráfica Nagy. São Paulo, 1983. 581p. 
CARVALHO, A. O tupi - na chorographia pernanbucana ed. Instituto Archeologico e Geográphico de Pernambuco. Recife, 1907. 82p.

COSTA, F. A. P. Anais pernambucano. Secretaria de Turismo, Cultura e Esportes Fundação do Patrimônio Histórico e Artístico de Pernambuco. Recife, 1983, v. 4. $85 \mathrm{p}$.

CUNHA, A. G. da. Dicionário histórico das palavras portuguesas de origem tupi. Companhia Melhoramentos. São Paulo, 4. ed. 1998. 357p.

FUNDAÇÃO NACIONAL DE SAÚDE. Relatório do inquérito sanitário em Pernambuco. 1996.

HEIZER, R. F. Etnológica brasileira - Etnobiologia. Venenos de Pesca. Editora Vozes. Rio de Janeiro, 1986. p. 95-99.

MELO P. P. Contribuição indígena à fala norte-rio-grandense. Instituto de Antropologia "Câmara Cascudo". Natal, 1971. 72p.

PALÁCIO, A. P. Memória etnolingüística. Boletim axéuvyru - Núcleo de Estudos Indigenistas da UFPE. v. 4, p. 13-14, 1987.

RIBEIRO, B. G. Dicionário do artesanato indígena. Editora da Universidade de São Paulo. São Paulo, 1988. 346p.

TIBIRIÇÁ, L. C. Dicionário tupi - português. Traço Editora. São Paulo, 1984. 200p. 